\title{
Complex Regulation and Function of the Inflammatory Smooth Muscle Cell Phenotype in Atherosclerosis
}

\author{
Anthony Wayne Orr ${ }^{\mathrm{a}}$ Nicole E. Hastings ${ }^{\mathrm{b}}$ Brett R. Blackman ${ }^{\mathrm{c}, \mathrm{e}}$ \\ Brian R. Wamhoff ${ }^{-\mathrm{e}}$ \\ ${ }^{a}$ Department of Pathology, Louisiana State University Health Sciences Center, Shreveport, La., ${ }^{\mathrm{b}}$ HemoShear, LLC, \\ and Departments of ${ }^{\mathrm{c} B i o m e d i c a l ~ E n g i n e e r i n g ~ a n d ~}{ }^{\mathrm{d}}$ Medicine, and ${ }^{\mathrm{e}}$ Robert M. Berne Cardiovascular Research \\ Center, University of Virginia, Charlottesville, Va., USA
}

\section{Key Words}

Atherosclerosis $\cdot$ Inflammation $\cdot$ Matrix $\cdot$ Smooth muscle $\cdot$

VCAM-1

\begin{abstract}
Vascular smooth muscle cell (SMC) phenotypic modulation plays a key role in atherosclerosis and is classically defined as a switch from a 'contractile' phenotype to a 'synthetic' phenotype, whereby genes that define the contractile SMC phenotype are suppressed and proliferation and/or migratory mechanisms are induced. There is also evidence that SMCs may take on a 'proinflammatory' phenotype, whereby SMCs secrete cytokines and express cell adhesion molecules, e.g. IL-8, IL-6, and VCAM-1, respectively, which may functionally regulate monocyte and macrophage adhesion and other processes during atherosclerosis. Factors that drive the inflammatory phenotype are not limited to cytokines but also include hemodynamic forces imposed on the blood vessel wall and intimate interaction of endothelial cells with SMCs, as well as changes in matrix composition in the vessel wall. However, it is critical to recognize that our understanding of the complex interaction of these multiple signal inputs has only recently begun to shed light on mechanisms that regulate the inflammatory SMC phenotype, primarily through
\end{abstract}

models that attempt to recreate this environment ex vivo. The goal of this review is to summarize our current knowledge in this area and identify some of the key unresolved challenges and questions requiring further study.

Copyright $\odot 2009$ S. Karger AG, Basel

\section{Introduction}

The vascular smooth muscle cell (SMC) possesses rather remarkable plasticity, being able to undergo phenotypic modulation during embryonic development, maturation of the adult blood vessels, and in response to

Previous articles in this special topic series: 1. Pohl U, Meininger G: Vascular update: a new review series. J Vasc Res 2009;46:503. 2. Hudlicka O, Brown MD: Adaptation of skeletal muscle microvasculature to increased or decreased blood flow: role of shear stress, nitric oxide and vascular endothelial growth factor. J Vasc Res 2009;46:504-512. 3. Krenzt AJ, Clough G, Byrne CD: Vascular disease in the metabolic syndrome: do we need to target the microcirculation to treat large vessel disease? J Vasc Res 2009;46:515-526. 4. Sen CK, Gordillo GM, Khanna S, Roy S: Micromanaging vascular biology: tiny microRNAs play big band. J Vasc Res 2009;46:527-540.

\section{KARGER}

(ㅇ) 2009 S. Karger AG, Basel

Fax +41613061234 E-Mail karger@karger.ch www.karger.com www.karger.com/jvr
Prof. Brian R. Wamhoff

Department of Biomedical Engineering

University of Virginia, MR4 RM6022

409 Lane Road, Charlottesville, VA 22908 (USA)

Tel. +1 434243 6525, Fax +1 434982 0055, E-Mail wamhoff@virginia.edu 
many environmental cues that often underlie vascular diseases such as atherosclerosis, in-stent restenosis, aneurysms, and tumor angiogenesis. If only for the economy of language, SMC phenotypic modulation is still classically described in the literature as a shift (sometimes a continuum) between a 'contractile' and 'synthetic' phenotype. Over the past 30 years, extraordinary progress has been made to further our understanding of the molecular mechanisms that regulate vascular SMC phenotypic modulation, including differentiation to a contractile state, de-differentiation, proliferation, and migration. In atherosclerosis, transition of SMCs from a contractile state to a proliferative and migratory state contributes to plaque growth. SMCs are also responsible for the formation of the fibrotic cap that can stabilize and prevent plaque rupture. Extensive reviews have been written on these topics and will not be discussed herein; we refer you to previous publications $[1,2]$ as a starting point. Inflammation plays a very important role in atherosclerosis. In fact, many would argue that atherosclerosis begins with activation of the endothelium, which includes an inflammatory response. As the disease progresses, vascular SMCs are in proximity to and physically interact with inflammatory cell types, e.g. monocytes and macrophages, which play a very important role in further exacerbating the disease (fig. 1a) [3]. Furthermore, histological images have shown that prior to the onset of complex plaque development in human tissues $[4,5]$ and experimental models of atherosclerosis, markers of inflammation are observed in SMCs in the media of the vessel wall, such as VCAM-1 (fig. 1b, c, respectively) and inflammatory transcriptional mediators, such as activated NF- $\kappa \mathrm{B}$ $[6,7]$. What is this SMC phenotype? Although there has not been a rigorous molecular phenotyping of these cells in vivo, it has been shown that SMCs which appear to be resident in the vascular media, neither proliferating nor migrating, can still express contractile markers of differentiation, e.g. $\alpha$-smooth muscle actin, as well as inflammatory genes such as VCAM-1. Is this phenotype truly distinct or a component of the continuum of SMC-phenotypic modulation between the contractile and synthetic states? The focus of this review is to provide an overview of the current state of knowledge of molecular mechanisms/processes that control the inflammatory SMC phenotype and the function of the inflammatory SMC phenotype in atherosclerosis. We wish to apologize in advance to our many outstanding colleagues whose work we may have either inadvertently overlooked or been unable to discuss in sufficient detail due to space constraints.

The Inflammatory Smooth Muscle Cell

\section{Molecular Signaling and Transcriptional Regulation of the Inflammatory SMC Phenotype}

Multiple stimuli within the atherosclerotic plaque are capable of promoting an inflammatory phenotype in SMCs. Hypercholesterolemia and dyslipidemia promote low density lipoprotein (LDL) accumulation within the vessel wall. In the setting of enhanced reactive oxygen species production, LDL becomes oxidized (oxLDL) enhancing its proinflammatory properties in endothelial cells, SMCs and monocytes [8]. While atherosclerotic progression is closely linked to systemic environmental risk factors, the local susceptibility of the vasculature to atherosclerosis is controlled by blood flow patterns [9, 10]. Vascular regions exposed to unidirectional laminar flow are protected from plaque development, whereas regions exposed to disturbed flow patterns, such as bifurcations, branch points, and curvatures, are prone to develop atherosclerotic plaques. The endothelial cells lining the vessel wall respond to the forces generated by blood flow, and the subsequent endothelial cell response to flow depends upon the specific flow pattern. Laminar flow patterns with high levels of time-averaged shear stresses promote endothelial production of $\mathrm{NO}$ and $\mathrm{PGI}_{2}$ inducing both vasodilatory and anti-inflammatory responses in SMCs. In contrast, disturbed flow patterns, marked by low levels of time-averaged shear stresses, promote endothelial cells to adopt a proinflammatory phenotype with enhanced expression of chemokines (e.g. IL-8 and MCP1) and cell adhesion molecules (e.g. VCAM-1 and ICAM1; fig. 2.1). The local expression of cell adhesion molecules and chemokines on the endothelial cell surface recruits blood monocytes that produce cytokines such as TNF $\alpha$ and IL-1 $\beta$ further propagating local inflammation [11]. Indeed, the importance of hemodynamic forces regulating the endothelium has been studied for over 20 years. As discussed below, recent studies by our group showed that induction of endothelial cell inflammation by disturbed hemodynamic forces plays a critical role in regulating SMC inflammation $[5,12]$. In addition to soluble factors, the local SMC environment can significantly affect the inflammatory response. Increased blood pressure in response to hypertension enhances the circumferential strain on SMCs through interactions between the SMCs and the surrounding matrix. In addition, changes in blood pressure affect local hemodynamics, regulating the SMC phenotype through changes in endothelial cell physiology [13]. Alterations in either the mechanical load or the content of the extracellular matrix also modulate proinflammatory gene expression [14-16]. 

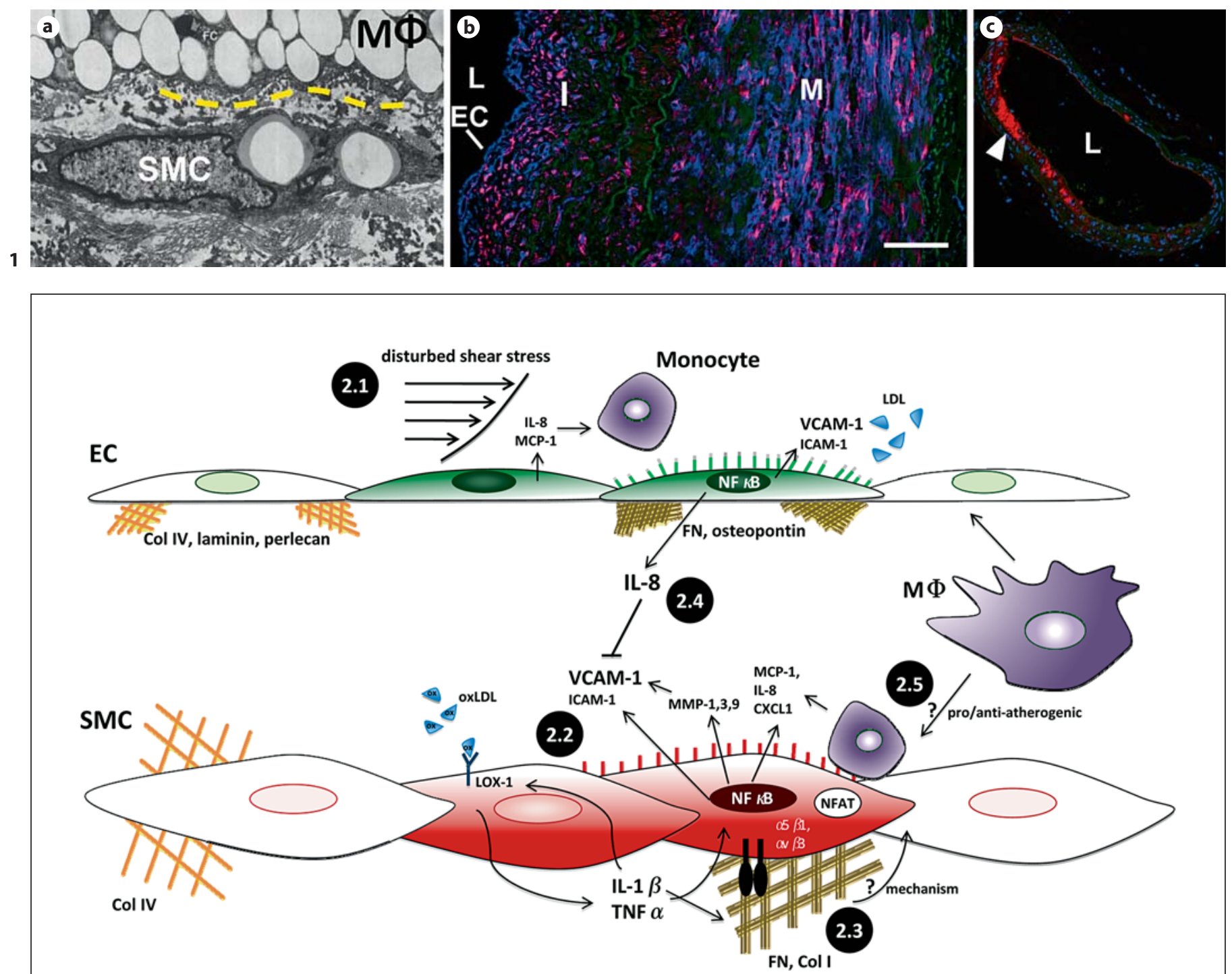

2

Fig. 1. SMCs can be in proximity to macrophages $(M \Phi)$ and express VCAM-1 in vascular disease. a SMCs within the neointima are in close proximity and can physically interact with other cell types, including endothelial cells, monocytes, and macrophages (yellow dashed line is the MФ/SMC interface; adapted from Stary et al. [3]). These interactions can influence SMC phenotype, promoting inflammatory responses. b SMCs present in the intimal and medial layers of human coronary arteries can express the adhesion molecule VCAM-1 (blue - VCAM- 1 , red - $\alpha$-smooth muscle actin, green - elastin; Hastings et al. [5]). c In the ApoE-/mouse, VCAM-1 expression is prevalent in the intimal regions of the inner curvature of the aortic arch, prior to lesion formation (red - VCAM-1, blue - nuclei, green - elastin [unpubl. observation]). $\mathrm{EC}=$ Endothelial cell; $\mathrm{I}=$ intima; $\mathrm{M}=$ media; $\mathrm{L}=$ lumen.

Fig. 2. Complex regulation and function of the inflammatory SMC phenotype in atherosclerosis. 2.1 Disturbed low, time-averaged shear stresses cause priming of endothelial cells (EC) towards a proinflammatory state, inducing proteins including IL-8,
MCP-1, VCAM-1, and ICAM-1. All of these proteins are involved in capture and firm adhesion of monocytes to the endothelium. 2.2 oxLDL binds to LOX-1, which can increase cytokine production (TNF $\alpha$, MCP-1, and IL-8) and adhesion molecule expression in NF-кB-dependent pathways. 2.3 The matrix that SMCs bind to can induce modulation towards a proinflammatory phenotype. Cytokines stimulate FN production which can activate NF- $\kappa$ B and/or NFAT through integrin signaling, though the direct mechanism inducing SMC inflammation is not well established. $2.4 \mathrm{It}$ remains unclear whether macrophage interaction with ECs and SMCs is having pro/anti-inflammatory effects on each cell phenotype. 2.5 Disturbed shear stresses are known to cause IL-8 secretion, which was recently demonstrated to inhibit expression of VCAM-1 in SMCs, thus demonstrating one mechanism by which a mechanical stimulus influences EC/SMC cross-talk, and ultimately the SMC inflammatory state. Green ECs and red SMCs indicate transition to the activated, inflammatory state. 
Therefore, the induction of the inflammatory SMC phenotype is likely multifactorial, ascribed to the combined and often synergistic effects of multiple inflammatory stimuli, as discussed further in this section.

\section{NF- $\kappa B$, NFAT, STAT - Transcriptional Regulators of Inflammation}

Proinflammatory stimuli, such as cytokines, oxLDL, Toll-like receptor ligands, and certain matrix proteins, all stimulate inflammatory gene expression through a remarkably conserved set of signaling pathways, including the stress-activated protein kinases $\mathrm{p} 38$ and JNK and the transcription factors NF- $\mathrm{B}, \mathrm{NFAT}$ and STAT1/3 [17]. While p38 signaling appears to play a major role in posttranscriptional regulation of inflammatory genes [18], JNK signaling stimulates proinflammatory gene expression through effects on transcription factors, most notably AP-1 [19]. Signaling through JNK is implicated in smooth muscle growth [20], apoptosis [21], migration [20], and the expression of proinflammatory genes such as VCAM-1 [22] and MCP-1 [23]. NF- $\kappa$ B refers to a family of heterodimeric transcription factors that regulate the expression of genes involved in inflammation, apoptosis, and proliferation. SMCs show constitutive binding of a p50-p50 homodimer to DNA, and this interaction has been shown to repress proinflammatory gene expression in multiple cell types $[24,25]$. Upon stimulation with proinflammatory cytokines, the p65-p50 heterodimer binds to target DNA stimulating gene expression [24]. Activated NF-kB has been observed in SMCs in both spontaneous atherosclerosis and after vessel injury [6, 7], and inhibiting NF- $\mathrm{\kappa B}$ reduces SMC proliferation in culture and neointima formation after balloon angioplasty [26]. Members of the NFAT family of transcription factors are typically maintained in an inactive phosphorylated state in the cytosol. Activation of the $\mathrm{Ca}^{2+}$-sensitive phosphatase calcineurin dephosphorylates NFAT to stimulate nuclear translocation and NFAT-dependent gene expression [27]. The major roles ascribed to NFAT in SMCs are the induction of proliferation and cell migration [27-29], and NFAT inhibition results in decreased injury-induced neointima formation [30]. While activation of the NFAT pathway is implicated in proinflammatory gene expression in other cell types, the role of NFAT in SMC inflammatory gene expression has received little attention thus far. However, NFAT activation is associated with the SMC expression of VCAM-1 and the proinflammatory cytokine IL-6 in vitro suggesting NFAT signaling is involved in the transition to an inflammatory SMC phenotype [14, 31-33]. While activation of the JAK-
STAT pathway is classically associated with cytokine receptor signaling, growth factor receptors, integrins, and G-protein-coupled receptors are also capable of activating JAK-STAT signaling. In SMCs, the ability of angiotensin (Ang) II to stimulate SMC proliferation and migration is dependent upon JAK-STAT signaling [34, 35]. While expression in healthy vessels is low, vascular injury results in a significant upregulation of JAK2 and STAT3 [36]. The JAK2 inhibitor AG490 is sufficient to reduce SMC proliferation and neointima formation [36]. In addition to effects on proliferation and migration, STAT3 is implicated in Ang II-induced expression of the IL-18 receptor [37] and in the IL-6-induced expression of MCP-1 [38], suggesting a role for JAK-STAT signaling in establishing the inflammatory SMC phenotype.

\section{Inflammation Begets Inflammation: The SMC}

Inflammatory Response to Soluble Mediators

One mechanism that induces SMC transition to an inflammatory phenotype is through oxLDL. Treating SMCs in culture with oxLDL stimulates the expression of chemokines (MCP-1 and CXCL1) [39, 40], cytokines (TNF $\alpha$ ) [40] and cell adhesion molecules (VCAM-1) [39] propagating the local inflammatory response. The oxLDL-induced expression of TNF $\alpha$ works in an autocrine fashion to induce the NF- $\kappa \mathrm{B}$-dependent expression of CXCL1 [40]. In addition to oxLDL-dependent cytokine production, the ability of SMCs to respond to oxLDL may be affected by proinflammatory cytokines since both IL-1 $\beta$ and TNF $\alpha$ stimulate the expression of the lectin-like oxLDL receptor (LOX-1; fig. 2.2) [41]. Recently, work by Miyoshi et al. [39] demonstrated that the responsiveness of SMCs to oxLDL is dependent upon the specific mouse strain. $\mathrm{C} 57 \mathrm{Bl} / 6 \mathrm{~J}$ mice are susceptible to diet- and injuryinduced plaque formation, while the $\mathrm{C} 3 \mathrm{H}$ strain is resistant to the formation of atherosclerotic plaques [42]. Although smooth muscle cells from both strains show an equal ability to oxidize LDL, the oxLDL-induced expression of MCP-1 and VCAM-1 is significantly enhanced in C57Bl/6J SMCs [39]. Therefore, the differential ability of oxLDL to promote the inflammatory smooth muscle phenotype between two mouse strains mimics their susceptibility to atherosclerotic plaque formation. Oxidized phospholipids, such as oxPOVPC that accumulates in atherosclerotic lesions, repress SMC differentiation while increasing type VIII collagen (Col8al) and inflammatory mediators such as MCP-1 and MCP-3 in both in vitro and in vivo model systems $[43,44]$.

The enhanced production of proinflammatory cytokines in atherosclerosis and the effect of cytokine signal- 
ing on SMC growth and migration have been well described elsewhere [reviewed in ref. 45, 46]. For example, IL- $1 \beta, T N F \alpha$, and IL- 8 have been shown to induce both growth and/or migration in human and rodent vascular SMCs under various cell culture conditions. As discussed later, though, SMC responses to cytokine treatment are context dependent, and depending on the cell culture conditions, results from groups can often be opposite. For example, Yue et al. [47] showed that IL-8 induces human SMC proliferation and migration whereas our group showed no growth or migratory response in human SMCs to IL-8 [5]. However different these functional responses, proinflammatory cytokines also promote SMCs to adopt a proinflammatory phenotype resulting in propagation of the local inflammatory response. Both IL-1 $\beta$ and TNF $\alpha$ stimulate the production of chemokines in SMCs, including IL-8 and MCP-1 [48-50], which promote the recruitment of $\mathrm{T}$ cells and monocytes into the growing plaque. Furthermore, SMCs express the MCP-1 receptor CCR-2 [51] and addition of exogenous MCP-1 to SMC cultures in vitro results in the NF- $\kappa \mathrm{B}$-dependent release of IL- 6 [52]. IL-1 $\beta$ and TNF $\alpha$ stimulate the NF- $\kappa B-d e-$ pendent expression of the cell adhesion molecules ICAM1 and VCAM-1 resulting in enhanced adhesion between SMCs and monocytes [53-55]. In contrast, IL-4 induces VCAM expression through an NF- $\kappa \mathrm{B}$-independent pathway [56], suggesting that alternative inflammatory signaling pathways can stimulate cell adhesion molecule expression. The interaction between monocytes and SMCs is sufficient to stimulate the expression of IL- 6 and MCP1 [57], suggesting that cell adhesion molecule expression in the SMC layer may propagate the local inflammatory response.

While most current research analyzes the cellular response to a single stimulus in culture, cells in vivo are exposed to multiple stimuli simultaneously and must adjust cellular responses to account for the whole of environmental stimuli. This point cannot be overstated and caution should be taken when interpreting results from monoculture studies, which are sometimes misleading. Therefore, it is not surprising that crosstalk between individual stimuli can significantly affect the SMC inflammatory phenotype. Both Ang II and activation of the thromboxane receptor synergizes with IL-1 $\beta$ to enhance VCAM-1 expression [22, 58]. In the case of Ang II, this effect is gene specific as IL-1 $\beta$-induced iNOS expression is inhibited by Ang II treatment [58] through a p38-dependent reduction in iNOS mRNA associated with reduced NF- $\kappa \mathrm{B}$ activation. In contrast to Ang II, activation of the thromboxane receptor stimulates VCAM-1 expres- sion through the JNK-dependent activation of the AP-1 transcription factor [22]. Activation of protein kinase A (PKA) by various mediators is generally associated with reduced inflammatory gene expression $[59,60]$. Activators of adenylate cyclase that produce cAMP to activate PKA inhibit the induction of ICAM-1 and VCAM-1 in SMCs by both TNF $\alpha$ and IL-1 $\beta$ [61]. Apolipoprotein E (ApoE) blocks IL-1 $\beta$-induced iNOS and COX-2 expression through the PKA-dependent inhibition of NF- $\kappa B$ and AP-1 [62]. Ligation of certain nuclear receptors, such as the estrogen receptor [63] or PPAR $\gamma$ [64], reduces proinflammatory gene expression as well. For the estrogen receptor, this reduction results from competition with $\mathrm{NF}-\mathrm{\kappa B}$ for binding to the transcriptional coactivator p300 [63]. While these studies suggest ordered communication between environmental signaling cues, the bevy of potential relationships and the precise mechanisms underlying this communication remain unknown.

\section{Matrix Composition in the SMC Inflammatory Phenotype}

The composition of the smooth muscle matrix affects multiple aspects of SMC function. SMC are normally surrounded by a basal lamina composed of collagen IV, laminin, and perlecan, and signals generated by the basal lamina prevent SMC growth and stimulate differentiation [65, 66] (fig. 2.3). In contrast, transitional matrix proteins such as fibronectin (FN) and osteopontin are deposited in the vessel wall during injury, and these transitional matrix proteins stimulate SMC growth through the ERK-dependent expression of cell cycle regulators $[65,66]$. However, recent work suggests matrix composition may similarly effect the transition to the inflammatory phenotype. TNF $\alpha$ and IL-1 $\beta$ both stimulate SMC FN expression [67], and attachment to FN stimulates transient activation of NF- $\mathrm{KB}$ [68]. Osteopontin deposition is enhanced in the atherosclerotic plaque, and osteopontin siRNA reduces Ang II-dependent secretion of IL6 through an NF- $\kappa \mathrm{B}$ - and AP-1-dependent mechanism [69]. Matrix-specific cellular responses are thought to occur through the integrin family of matrix receptors. The integrins $\alpha_{5} \beta_{1}$ and $\alpha_{v} \beta_{3}$ are associated with binding to these transitional matrix proteins and are implicated in the enhanced proliferation and migration associated with wound-induced neointima formation [70, 71]. These integrins also stimulate NF- $\kappa \mathrm{B}$ activation in other cell types [72, 73], but their role in SMC inflammation remains relatively unexplored. In contrast, the non-integrin matrix receptor CD44 is implicated in the transition to a proinflammatory phenotype. CD44 binds to hyal- 
uronic acid in the matrix, which shows higher expression in the atherosclerotic plaque [74]. Hyaluronic acid stimulates SMC VCAM-1 expression, and CD44 deficiency reduces atherosclerosis and VCAM-1 expression in the ApoE knockout mouse [74].

The role of the interstitial matrix in SMC biology is more complex than the protective basal laminae and the proinflammatory transitional matrix. While present under healthy conditions, SMC interaction with the interstitial matrix is thought to occur after the pericellular basal lamina has been degraded. In atherosclerosis, SMCs express collagen I and collagen III contributing to the local fibrotic response in the plaque. Polymerized collagen I reduces SMC growth and migration and is generally associated with a differentiated SMC phenotype $[65,75]$. In contrast, monomeric collagen I reduces SMC differentiation and promotes an inflammatory phenotype $[14,76]$. Activation of NF- $\kappa \mathrm{B}$ in SMCs results in the expression of MMP-1, MMP-3, and MMP-9 that degrade the polymerized collagen fibrils releasing monomeric collagen [77]. Adhesion to monomeric collagen I results in a marked and sustained increase in VCAM-1 expression compared to cells on the basal lamina-associated collagen IV [14]. Unlike cytokines that appear to stimulate VCAM-1 expression through an NF- $\mathrm{kB}$-dependent pathway, collagen I-induced VCAM-1 expression is insensitive to NF$\kappa B$ inhibitors [14]. Paradoxically, the induction of VCAM1 on collagen I requires the NF- $\kappa \mathrm{B}$ binding site. Recent work by Minami et al. [78] demonstrated that the NF- $\kappa B$ binding sites on the VCAM-1 promoter can also bind to the transcription factor NFAT. Monomeric collagen I stimulates a rapid $(<24 \mathrm{~h})$ increase in NFAT activation compared to collagen IV, and the calcineurin inhibitors cyclosporin A and A-285222 [31] both completely block collagen I-induced VCAM expression [14]. These data suggest that matrix composition and soluble cytokines promote VCAM-1 expression through different mechanisms (fig. 2.3).

One remaining question in collagen-induced VCAM1 expression is the identity of the receptors involved. Collagen I and collagen IV bind to similar integrins, although $\alpha_{2} \beta_{1}$ integrins show preference for collagen I while $\alpha_{1} \beta_{1}$ integrins preferentially bind to collagen IV [79]. Interestingly, ligation of $\alpha_{2} \beta_{1}$ by the snake venom toxin aggretin was recently shown to stimulate SMC growth and migration through the activation of NF- $\kappa \mathrm{B}$ [80]. In addition, healthy SMCs show high levels of $\alpha_{1} \beta_{1}$ expression, while both in vitro and in vivo model systems demonstrate enhanced $\alpha_{2} \beta_{1}$ expression in SMCs during phenotypic modulation [81]. The discoidin domain receptors DDR1 and DDR2 are transmembrane collagen receptors, and therefore may also mediate the differential effects of collagen I and collagen IV. Mice deficient in DDR1 show reduced SMC migration to collagen I and reduced expression of MMP-2 and MMP-9 [82]. Interestingly, mice deficient in both DDR1 and the LDL receptor show reduced atherosclerosis compared to LDL receptor null mice, characterized by reduced macrophage content within the plaque [83]. More work will be required to define the specific receptors and molecular mechanisms underlying the collagen I-induced transition to the inflammatory phenotype (fig. 2.3).

\section{'Forcing' the Smooth Muscle Inflammatory Phenotype: The Role of Shear Stress and Strain}

As we stated above, caution must be taken when interpreting monoculture cell studies and single stimuli. Cells dispersed from organs rarely behave like they do in vivo and the cell phenotype in vivo is often dictated by many factors. In the vasculature, elegant studies from the Gimbrone Laboratory (Brigham and Women's Hospital) and others have shown that the pulsatile nature of blood flow and the forces imposed on the endothelium can recapitulate endothelial cell phenotype ex vivo $[9,84]$. Flowing blood generates a tangential frictional force termed shear stress that endothelial cells respond to. Endothelial cells exposed to shear stress produce multiple factors that are known to promote SMC migration in SMC monoculture studies, such as PDGF-BB and IL-1 $\alpha$ [85]. As mentioned previously, in humans and animal models, atherosclerosis preferentially develops in regions of the vasculature where hemodynamic shear forces are disturbed, including regions where arteries bifurcate, e.g. the carotid sinus, and areas of extreme curvature, e.g. the inner region of the aortic arch. To illustrate the importance of regionspecific hemodynamic shear forces in regulating cell phenotype, Dai et al. [86] generated hemodynamic flow patterns from human subjects where atherosclerosis develops and flow is disturbed (the carotid sinus) and where atherosclerosis does not develop and shear forces are high (the common carotid artery), and applied these wave forms to endothelial cells in cell culture using a cone and plate viscometer [86, 87]. Results from these studies showed that disturbed hemodynamic flow induces endothelial priming towards inflammation, whereas high pulsatile shear stress patterns promote the quiescent endothelial cell phenotype (fig. 2.1). 
Recently our group showed that when human endothelial cells are grown in coculture with SMCs, application of an atheroprone, carotid sinus flow increases IL-8 secretion from endothelial cells which was associated with an increase in VCAM-1 expression in both endothelial cells and SMCs [12]. When monocytes were introduced into the system, increased monocyte adhesion was observed in both endothelial cells and SMCs exposed to disturbed hemodynamic waveforms compared to atheroprotective waveforms. Further analysis of the role of endothelial-derived IL-8 in the SMC expression of VCAM1 demonstrated a surprising anti-inflammatory role for IL-8 (fig. 2.4). Blocking IL-8 secretion from the endothelium by either siRNA or anti-IL-8 prevented flow-induced secretion of IL- 8 and potentiated flow-induced endothelial and SMC VCAM-1 expression [5]. Treating SMCs with IL-8 did not induce VCAM-1 expression, while treating cells with both IL- $1 \beta$ and IL- 8 reduced VCAM-1 expression compared to cells treated with IL-1 $\beta$ alone. This induction of VCAM- 1 by IL- $1 \beta$ requires $\mathrm{p} 38$ activity, and IL- 8 reduces IL- $1 \beta$-induced p38 signaling suggesting a potential mode of action [5]. This intricate signaling between the endothelium and SMCs is very difficult to tease out in intact arteries, and furthermore, in rodents, these studies are further challenged by the fact that mice and rats do not express the IL- 8 gene.

Other forces, including circumferential strain that affects both endothelial cells and SMCs during the cardiac cycle, can play a role in vascular responses [16]. Experimental analysis of the smooth muscle response to stretch suggests that a certain degree of stretch is required to maintain the differentiated SMC phenotype [88]. However, too little or too much stretch both result in SMC proliferation and the induction of inflammatory genes $[15,16]$. Exposing vascular SMCs to pulsatile stretch in culture stimulates NF- $\kappa \mathrm{B}$ activation through an oxidative stress-dependent pathway [89]. Stretch-induced production of reactive oxygen species stimulates MCP-1 expression through an ERK- and p38-dependent mechanism [90], suggesting stretch may utilize multiple signaling pathways to induce inflammatory gene expression. Vascular SMCs align parallel to the stretching force, and application of uniaxial stretch polarizes Rac activity to mediate this alignment response [91]. Since Rac also stimulates reactive oxygen species production through the NADPH oxidase complex [92], this remodeling stimulus may similarly be involved in the inflammatory phenotype. As such, Rac signaling is implicated in stretchinduced IL-6 expression through activation of both p38 and NF- $\mathrm{B}$ [93]. Interestingly, force-induced SMC align- ment is also a function of shear forces on the endothelium $[12,94]$, suggesting that endothelial cells may play an important role in generating the spatial cues necessary to direct SMC-adaptive signaling [12].

It is now apparent that observations in monoculture studies with single stimuli are only scratching the surface of what may be going on in an intact blood vessel. Because it is very difficult to dissect how multiple signals are integrated in vivo, developing models that attempt to recapitulate human in vivo cell phenotypes ex vivo will allow for a more detailed understanding of the factors and mechanisms that regulate not only SMC phenotype in atherosclerosis, but endothelial cells and macrophages and the delicate interactions in signaling occurring between these cells types (fig. 1,2).

\section{Is Posttranslational Regulation of the Inflammatory SMC Phenotype Important?}

\section{mRNA Stability in the Inflammatory Phenotype}

In addition to transcriptional regulation, protein expression often depends upon multiple posttranscriptional regulatory steps that affect mRNA stability and translation. MicroRNAs are evolutionarily conserved short RNA sequences that function to silence the expression of target genes, either through preventing translation or by inducing degradation. The miR-126 regulates VCAM-1 expression in endothelial cells [95]; however miR-126 expression in SMCs has not been described. The microRNA miR-155 is emerging as a key regulator of inflammatory gene expression in leukocytes and lymphocytes [96, 97]. In leukocytes, expression of miR-155 is induced by lipopolysaccharides, TNF $\alpha$, and IFN- $\gamma[98,99]$ and is thought to represent a negative feedback pathway, as miR-155 reduces the expression of components of the TLR and cytokine signaling pathways such as FADD, RIP, and IKK [98]. Smooth muscle cells show constitutive expression of miR-155, and the Ang II type I receptor is translationally repressed by miR-155 in SMCs [100]. However, the relevance of miR-126 and miR-155 to the SMC inflammatory phenotype is currently unknown and should provide an interesting target for future research.

In addition to microRNAs, the presence of adenylate uridylate-rich elements (AREs), usually located in the 3' untranslated region of mRNAs, regulates mRNA stability by affecting its degradation [101]. Many inflammatory proteins are encoded by ARE-containing mRNAs, including ICAM-1, VCAM-1, TNF $\alpha$, IL-1 $\beta$, IL- 8 , and MCP1 among others, consistent with the need to rapidly and 
efficiently modulate the expression of these genes [18, 102-104]. AREs affect mRNA stability through multiple ARE-binding proteins (i.e. HuR, AUF1, and TTP) that can function to either reduce or enhance the stability of the target mRNA sequences [101]. HuR generally protects ARE-containing transcripts from degradation, while AUF1 and TTP destabilize target mRNA. These effects appear to be gene specific, as AUF1 binding destabilizes IL-3 mRNA [105] while TTP destabilizes TNF $\alpha$ and GMCSF mRNA $[106,107]$. Many of the ARE-binding proteins are regulated by phosphorylation. For example, the stress-activated kinase p38 induces MAPKAP kinase 2 (MK2)-dependent phosphorylation of TTP $[108,109]$ resulting in the recruitment of the 14-3-3 family of adaptor molecules. Binding of 14-3-3 to TTP blocks the interaction with the 'decay machinery' and prevents TTP dephosphorylation by protein phosphatase $2 \alpha$ thereby promoting mRNA stability $[109,110]$. MK2 knockdown suppresses IL-1 $\beta$-induced VCAM-1 and MCP-1 expression, and the MK2 knockout shows reduced hypercholesterolemia-induced atherosclerosis [103].

Some inflammatory stimuli appear to specifically target mRNA stability to induce inflammatory gene expression either alone or synergistically with other stimuli. VCAM-1 expression in response to TNF $\alpha$ in synoviocytes can be sustained at the posttranscriptional level by the cotreatment with IL-4 or IL-13 [111]. IL-8 reduces both $\mathrm{p} 38$ phosphorylation and VCAM-1 expression in response to IL-1 $\beta$ [5]. However, the role of p38 signaling in VCAM-1 mRNA stability has yet to be explored in this system. We recently demonstrated that collagen I stimulates a sustained increase in VCAM-1 expression, and this effect may also involve posttranscriptional regulation. Plating SMCs on a collagen I matrix results in a rapid $(\sim 6 \mathrm{~h})$ increase in the activity of the VCAM-1 promoter measured using a luciferase construct [14]. However this enhanced activity was reduced to basal levels by $24 \mathrm{~h}$ [14]. Despite this, levels of VCAM-1 mRNA and protein continued to climb for at least 5 days. One explanation for this discrepancy is that collagen I promotes VCAM-1 mRNA stability. Activation of $\mathrm{p} 38$ and subsequent TTP phosphorylation is one way to accomplish this, however p38 activation was similar between matrices [14].

\section{Translational Control of Inflammatory Genes}

Regulation of mRNA translation represents another means of posttranscriptional control. Protein translation is classically regulated by the mammalian target of the rapamycin (mTOR) pathway [recently reviewed in ref. $112,113]$. Binding of eIF-4E to the $5^{\prime}$ mRNA cap recruits
eIF-4G to stimulate the formation of the eIF-4F complex and initiate cap-dependent translation. The interaction between eIF-4E and eIF-4G is blocked by $4 \mathrm{E}-\mathrm{BP} 1$. Phosphorylation of $4 \mathrm{E}-\mathrm{BP} 1$, most commonly by mTOR, reduces $4 \mathrm{E}-\mathrm{BP} 1$ binding to eIF-4E thereby enhancing translation. Rapamycin is currently in use as an immunosuppressant due to its potent growth-inhibitory effects. Several inflammatory stimuli activate mTOR, although little is known concerning the role of mTOR in inflammatory gene expression. In response to TNF $\alpha, \mathrm{mTOR}$ inhibition blocked the expression of IL- 6 but did not affect the expression of IL-8 or MCP-1 [114]. An alternative mechanism of translational regulation is the activation of MAP kinase signal-integrating kinase-1 (Mnk-1), a substrate of both p38 and ERK MAP kinases that phosphorylates eIF-4E on Ser209 enhancing its affinity for the mRNA cap $[115,116]$. Mouse macrophages require Mnkdependent eIF-4E phosphorylation for lipopolysaccharide-induced TNF $\alpha$ production [117]. TNF $\alpha$ and IL-1 $\beta$ stimulate eIF-4E phosphorylation through the p38-dependent Mnk1 activation, and Mnk1 inhibition prevents IL-1 $\beta$ and anisomycin-induced release of proinflammatory cytokines, including IL-1 $\beta, \mathrm{TNF} \alpha$, and IL- 6 [118, 119]. In addition to eIF-4E, Mnk phosphorylates the ARE-binding protein hnRNP Al, and this phosphorylation stabilizes TNF $\alpha$ mRNA in T cells [120]. While a role for Mnk signaling in the SMC inflammatory phenotype has not been described, Mnk proteins are expressed in SMCs and ERK-dependent Mnk-1 activation was shown to be required for angiotensin II-induced SMC protein synthesis and hypertrophy [121]. The involvement of Mnk signaling in SMC inflammatory gene expression is an intriguing target for future research.

\section{Concluding Remarks}

Will targeting vascular inflammation reduce atherosclerosis? Agents that block SMC proliferation have been shown to be effective in reducing in-stent restenosis and atherosclerosis, but will this apply to agents that block inflammation? Targeting one inflammatory pathway may be insufficient to reduce the inflammatory phenotype. However, given the importance of p38 signaling in the posttranscriptional control of the inflammatory response, it is not surprising that three p38 inhibitors (SCIO469, VX-702, and BIRB-796) are currently in clinical trials for the treatment of chronic inflammatory diseases such as Crohn's disease and rheumatoid arthritis $[17,122]$. Secondary clinical outcomes such as carotid in- 
tima media thickness may shed light on whether such therapies can also reduce atherosclerosis. Interestingly, statins, specifically Crestor (rosuvastatin calcium), was recently shown in the Jupiter Trial to reduce C-reactive protein, a biomarker for systemic inflammation, in addition to its primary effect of lowering cholesterol. What is interesting, though, is that there are little data showing that statins decrease vascular wall inflammation in vivo. Thus, although we have presented compelling evidence that the inflammatory SMC phenotype is important in atherosclerosis, therapeutic targeting of this cell type is in its infancy. In fact, to these authors, it is not clear if there are any therapies in development that are designed to directly target the vascular wall for preventing atherosclerosis. All therapies to date decrease atherosclerosis by treating the factors associated with the development of the disease, such as cholesterol, triglycerides, diabetes, and hypertension.

Can vascular inflammation be used to diagnose atherosclerosis? The field of molecular imaging has taken advantage of cell surface markers associated with inflammation, such as VCAM-1, to develop antigen-recognition imaging modalities for diagnosing regions of vascular inflammation and atherosclerosis and potential spatial monitoring of anti-VCAM-1 pharmacotherapy [123]. It is also plausible that small molecule compounds, drug therapies, and gene therapy can be delivered to inflamed blood vessels using VCAM-1 molecular-targeted microbubble/contrast agent carriers [124, 125].

Is SMC interaction with macrophages during the development of atherosclerosis good or bad? Endothelial cell interaction with SMCs at the myoendothelial cell junction is very important in regulating tone and vessel homeostasis and healthy cell phenotype. Conventional wisdom would suggest that monocyte/macrophage interaction with SMCs in atherosclerosis is bad but there is no definitive proof of this (fig. 2.5). Studies have shown that SMCs can function to stabilize monocytes/macrophages and prevent apoptosis, a good thing? [126]. Indeed, the inherent plasticity of the vascular SMC is often viewed as a means to repair or heal the vascular wall in response to vascular injury and chemical stimuli. Emerging evidence for a population of anti-inflammatory macrophages (Ly-6C $\mathrm{C}^{\text {lo }}$ monocytes in mouse, $\mathrm{CD} 14+\mathrm{CD} 16+$ monocytes in humans) as negative regulators of atherosclerosis also clouds the predicted function of SMC-dependent macrophage retention model in the progression of atherosclerosis [127].

Lastly, what are the specific receptors and molecular mechanisms underlying matrix-induced transition to the inflammatory phenotype (fig. 2.3)?
Other major challenges include dissecting out the multiple signaling pathways that regulate vascular SMC phenotype in vivo during the progression of atherosclerosis. It is likely that major progress in this area is going to be dependent on the development of sophisticated lossof-function approaches including SMC-specific conditional gene knockout models and/or local inhibition of candidate regulatory factors/pathways specifically at sites of lesion formation [128]. These in vivo tasks are not trivial and perhaps the ex vivo coculture models discussed above will allow researchers to further understand these complex mechanisms.

\section{Acknowledgments}

We acknowledge the outstanding support of the University of Virginia Robert M. Berne Cardiovascular Research Center and the Department of Biomedical Engineering and our many good friends and colleagues in the field for their many outstanding studies and creative ideas that we hope have been captured in this review.

This work was supported by NIH grants HL081682 (to B.R.W.), HL082836 and HL080956 (to B.R.B.); the American Heart Association Scientist Development Grant (to B.R.W. and A.W.O.) and the University of Virginia Funds for Excellence in Science and Technology and the Cardiovascular Division Partners' Fund Award (to B.R.W. and B.R.B.).

References

1 Gerthoffer WT: Mechanisms of vascular smooth muscle cell migration. Circ Res 2007; 100:607-621.

- Owens GK, Kumar MS, Wamhoff BR: Molecular regulation of vascular smooth muscle cell differentiation in development and disease. Physiol Rev 2004;84:767-801.

-3 Stary HC, Chandler AB, Glagov S, Guyton JR, Insull W Jr, Rosenfeld ME, Schaffer SA, Schwartz CJ, Wagner WD, Wissler RW: A definition of initial, fatty streak, and intermediate lesions of atherosclerosis. A report from the Committee on Vascular Lesions of the Council on Arteriosclerosis, American Heart Association. Arterioscler Thromb 1994;14:840-856

4 Torzewski M, Navarro B, Cheng F, Canisius A, Schmidt T, Bhakdi S, Urban R, Lackner KJ: Investigation of Sudan IV staining areas in aortas of infants and children: possible prelesional stages of atherogenesis. Atherosclerosis 2009;206:159-167.

$\checkmark 5$ Hastings NE, Feaver RE, Lee MY, Wamhoff BR, Blackman BR: Human IL-8 regulates smooth muscle cell VCAM-1 expression in response to endothelial cells exposed to atheroprone flow. Arterioscler Thromb Vasc Biol 2009;29:725-731.

Orr/Hastings/Blackman/Wamhoff 
-6 Brand K, Page S, Rogler G, Bartsch A, Brandl R, Knuechel R, Page M, Kaltschmidt C, Baeuerle PA, Neumeier D: Activated transcription factor nuclear factor-kappa B is present in the atherosclerotic lesion. J Clin Invest 1996;97:1715-1722.

7 Landry DB, Couper LL, Bryant SR, Lindner $\mathrm{V}$ : Activation of the NF-kappa B and I kappa B system in smooth muscle cells after rat arterial injury. Induction of vascular cell adhesion molecule-1 and monocyte chemoattractant protein-1. Am J Pathol 1997;151: 1085-1095.

8 Steinberg D: Atherogenesis in perspective: hypercholesterolemia and inflammation as partners in crime. Nat Med 2002;8:12111217.

-9 Gimbrone MA Jr, Topper JN, Nagel T, Anderson KR, Garcia-Cardena G: Endothelial dysfunction, hemodynamic forces, and atherogenesis. Ann NY Acad Sci 2000;902:230239, discussion 239-240.

10 Glagov S, Zarins C, Giddens DP, Ku DN: Hemodynamics and atherosclerosis. Insights and perspectives gained from studies of human arteries. Arch Pathol Lab Med 1988;112: 1018-1031.

-11 Malek AM, Alper SL, Izumo S: Hemodynamic shear stress and its role in atherosclerosis. JAMA 1999;282:2035-2042.

-12 Hastings NE, Simmers MB, McDonald OG, Wamhoff BR, Blackman BR: Atherosclerosis-prone hemodynamics differentially regulates endothelial and smooth muscle cell phenotypes and promotes pro-inflammatory priming. Am J Physiol Cell Physiol 2007; 293:C1824-C1833.

13 Mitchell GF, Pfeffer MA: Pulsatile hemodynamics in hypertension. Curr Opin Cardiol 1999; 14:361-369.

-14 Orr AW, Lee MY, Lemmon JA, Yurdagul A Jr, Gomez MF, Bortz PD, Wamhoff BR: Molecular mechanisms of collagen isotype-specific modulation of smooth muscle cell phenotype. Arterioscler Thromb Vasc Biol 2009; 29:225-231.

-15 Birukov KG, Bardy N, Lehoux S, Merval R, Shirinsky VP, Tedgui A: Intraluminal pressure is essential for the maintenance of smooth muscle caldesmon and filamin content in aortic organ culture. Arterioscler Thromb Vasc Biol 1998;18:922-927.

$\checkmark 16$ Lehoux S, Castier Y, Tedgui A: Molecular mechanisms of the vascular responses to haemodynamic forces. J Intern Med 2006; 259:381-392.

-17 O’Neill LA: Targeting signal transduction as a strategy to treat inflammatory diseases. Nat Rev Drug Discov 2006;5:549-563.

-18 Pietersma A, Tilly BC, Gaestel M, de Jong N, Lee JC, Koster JF, Sluiter W: p38 mitogen activated protein kinase regulates endothelial VCAM-1 expression at the post-transcriptional level. Biochem Biophys Res Commun 1997;230:44-48.
19 Johnson GL, Nakamura K: The c-jun kinase/ stress-activated pathway: regulation, function and role in human disease. Biochim Biophys Acta 2007;1773:1341-1348.

20 Kavurma MM, Khachigian LM: ERK, JNK, and p38 MAP kinases differentially regulate proliferation and migration of phenotypically distinct smooth muscle cell subtypes. J Cell Biochem 2003;89:289-300.

-21 Sotoudeh M, Li YS, Yajima N, Chang CC, Tsou TC, Wang Y, Usami S, Ratcliffe A, Chien S, Shyy JY: Induction of apoptosis in vascular smooth muscle cells by mechanical stretch. Am J Physiol Heart Circ Physiol 2002;282:H1709-H1716.

22 Bayat H, Xu S, Pimentel D, Cohen RA, Jiang B: Activation of thromboxane receptor upregulates interleukin (IL)-1 $\beta$-induced VCAM-1 expression through JNK signaling. Arterioscler Thromb Vasc Biol 2008;28:127134.

23 Chen YM, Chiang WC, Lin SL, Wu KD, Tsai TJ, Hsieh BS: Dual regulation of tumor necrosis factor- $\alpha$-induced CCL2/monocyte chemoattractant protein-1 expression in vascular smooth muscle cells by nuclear factor $-\kappa \mathrm{B}$ and activator protein-1: modulation by type III phosphodiesterase inhibition. J Pharmacol Exp Ther 2004;309:978-986.

-24 Bourcier T, Sukhova G, Libby P: The nuclear factor kappa-B signaling pathway participates in dysregulation of vascular smooth muscle cells in vitro and in human atherosclerosis. J Biol Chem 1997;272:1581715824.

25 Cao S, Zhang X, Edwards JP, Mosser DM: NF- $\mathrm{B} 1$ (p50) homodimers differentially regulate pro- and anti-inflammatory cytokines in macrophages. J Biol Chem 2006;281: 26041-26050.

26 Autieri MV, Yue TL, Ferstein GZ, Ohlstein E: Antisense oligonucleotides to the p 65 subunit of NF-kB inhibit human vascular smooth muscle cell adherence and proliferation and prevent neointima formation in rat carotid arteries. Biochem Biophys Res Commun 1995;213:827-836.

27 Nilsson LM, Nilsson-Ohman J, Zetterqvist AV, Gomez MF: Nuclear factor of activated T-cells transcription factors in the vasculature: the good guys or the bad guys? Curr Opin Lipidol 2008;19:483-490.

28 Liu Z, Dronadula N, Rao GN: A novel role for nuclear factor of activated $\mathrm{T}$ cells in receptor tyrosine kinase and $\mathrm{G}$ protein-coupled receptor agonist-induced vascular smooth muscle cell motility. J Biol Chem 2004;279: 41218-41226.

-29 Yellaturu CR, Ghosh SK, Rao RK, Jennings LK, Hassid A, Rao GN: A potential role for nuclear factor of activated T-cells in receptor tyrosine kinase and G-protein-coupled receptor agonist-induced cell proliferation. Biochem J 2002;368:183-190.
30 Liu Z, Zhang C, Dronadula N, Li Q, Rao GN: Blockade of nuclear factor of activated T cells activation signaling suppresses balloon injury-induced neointima formation in a rat carotid artery model. J Biol Chem 2005;280: 14700-14708.

31 Nilsson LM, Sun ZW, Nilsson J, Nordstrom I, Chen YW, Molkentin JD, Wide-Swensson D, Hellstrand P, Lydrup ML, Gomez MF: Novel blocker of NFAT activation inhibits IL- 6 production in human myometrial arteries and reduces vascular smooth muscle cell proliferation. Am J Physiol Cell Physiol 2007;292:C1167-C1178.

>32 Orr AW, Sanders JM, Bevard M, Coleman E, Sarembock IJ, Schwartz MA: The subendothelial extracellular matrix modulates NF$\kappa \mathrm{B}$ activation by flow: a potential role in atherosclerosis. J Cell Biol 2005;169:191-202.

33 Abbott KL, Loss JR 2nd, Robida AM, Murphy TJ: Evidence that $\mathrm{G} \alpha_{\mathrm{q}}$-coupled receptorinduced interleukin- 6 mRNA in vascular smooth muscle cells involves the nuclear factor of activated T cells. Mol Pharmacol 2000; 58:946-953.

-34 Neeli I, Liu Z, Dronadula N, Ma ZA, Rao GN: An essential role of the Jak-2/STAT-3/cytosolic phospholipase $\mathrm{A}_{2}$ axis in platelet-derived growth factor $\mathrm{BB}$-induced vascular smooth muscle cell motility. J Biol Chem 2004;279:46122-46128.

\35 Marrero MB, Schieffer B, Li B, Sun J, Harp JB, Ling BN: Role of Janus kinase/signal transducer and activator of transcription and mitogen-activated protein kinase cascades in angiotensin II- and platelet-derived growth factor-induced vascular smooth muscle cell proliferation. J Biol Chem 1997; 272:24684-24690.

36 Seki Y, Kai H, Shibata R, Nagata T, Yasukawa $\mathrm{H}$, Yoshimura A, Imaizumi T: Role of the JAK/STAT pathway in rat carotid artery remodeling after vascular injury. Circ Res 2000;87:12-18.

37 Sahar S, Dwarakanath RS, Reddy MA, Lanting L, Todorov I, Natarajan R: Angiotensin II enhances interleukin-18 mediated inflammatory gene expression in vascular smooth muscle cells: a novel cross-talk in the pathogenesis of atherosclerosis. Circ Res 2005;96: 1064-1071.

$>38$ Watanabe S, Mu W, Kahn A, Jing N, Li JH, Lan HY, Nakagawa T, Ohashi R, Johnson RJ: Role of JAK/STAT pathway in IL-6-induced activation of vascular smooth muscle cells. Am J Nephrol 2004;24:387-392.

-39 Miyoshi T, Tian J, Matsumoto AH, Shi W: Differential response of vascular smooth muscle cells to oxidized LDL in mouse strains with different atherosclerosis susceptibility. Atherosclerosis 2006;189:99-105. 
40 Barlic J, Zhang Y, Murphy PM: Atherogenic lipids induce adhesion of human coronary artery smooth muscle cells to macrophages by up-regulating chemokine CX3CL1 on smooth muscle cells in a TNF $\alpha-\mathrm{NF \kappa B}$-dependent manner. J Biol Chem 2007;282: 19167-19176.

41 Hofnagel O, Luechtenborg B, Stolle K, Lorkowski S, Eschert H, Plenz G, Robenek H: Proinflammatory cytokines regulate LOX-1 expression in vascular smooth muscle cells. Arterioscler Thromb Vasc Biol 2004;24: 1789-1795.

42 Daugherty A: Mouse models of atherosclerosis. Am J Med Sci 2002;323:3-10.

-43 Cherepanova OA, Pidkovka NA, Sarmento OF, Yoshida T, Gan Q, Adiguzel E, Bendeck MP, Berliner J, Leitinger N, Owens GK: Oxidized phospholipids induce type VIII collagen expression and vascular smooth muscle cell migration. Circ Res 2009;104:609-618.

- 44 Pidkovka NA, Cherepanova OA, Yoshida T, Alexander MR, Deaton RA, Thomas JA, Leitinger N, Owens GK: Oxidized phospholipids induce phenotypic switching of vascular smooth muscle cells in vivo and in vitro. Circ Res 2007;101:792-801.

45 Raines EW, Ferri N: Thematic review series: The immune system and atherogenesis. Cytokines affecting endothelial and smooth muscle cells in vascular disease. J Lipid Res 2005;46:1081-1092.

-46 Doran AC, Meller N, McNamara CA: Role of smooth muscle cells in the initiation and early progression of atherosclerosis. Arterioscler Thromb Vasc Biol 2008;28:812-819.

-47 Yue TL, Wang X, Sung CP, Olson B, McKenna PJ, Gu JL, Feuerstein GZ: Interleukin8. A mitogen and chemoattractant for vascular smooth muscle cells. Circ Res 1994;75: $1-7$.

-48 Jung YD, Fan F, McConkey DJ, Jean ME, Liu W, Reinmuth N, Stoeltzing O, Ahmad SA, Parikh AA, Mukaida N, Ellis LM: Role of P38 MAPK, AP-1, and NF- $\kappa$ B in interleukin- $1 \beta$ induced IL-8 expression in human vascular smooth muscle cells. Cytokine 2002;18:206213.

49 Libby P, Sukhova G, Lee RT, Galis ZS: Cytokines regulate vascular functions related to stability of the atherosclerotic plaque. J Cardiovasc Pharmacol 1995;25 (suppl 2):S9S12.

-50 Wang Z, Castresana MR, Newman WH: NF$\kappa \mathrm{B}$ is required for TNF- $\alpha$-directed smooth muscle cell migration. FEBS Lett 2001;508: 360-364.

51 Hayes IM, Jordan NJ, Towers S, Smith G, Paterson JR, Earnshaw JJ, Roach AG, Westwick J, Williams RJ: Human vascular smooth muscle cells express receptors for CC chemokines. Arterioscler Thromb Vasc Biol 1998; 18:397-403.
52 Viedt C, Vogel J, Athanasiou T, Shen W, Orth SR, Kubler W, Kreuzer J: Monocyte chemoattractant protein-1 induces proliferation and interleukin- 6 production in human smooth muscle cells by differential activation of nuclear factor- $\mathrm{\kappa B}$ and activator protein-1. Arterioscler Thromb Vasc Biol 2002; 22:914-920.

53 Braun M, Pietsch P, Felix SB, Baumann G: Modulation of intercellular adhesion molecule-1 and vascular cell adhesion molecule- 1 on human coronary smooth muscle cells by cytokines. J Mol Cell Cardiol 1995;27:25712579.

54 Couffinhal T, Duplaa C, Moreau C, Lamaziere JM, Bonnet J: Regulation of vascular cell adhesion molecule-1 and intercellular adhesion molecule-1 in human vascular smooth muscle cells. Circ Res 1994;74:225234.

-55 Thorne SA, Abbot SE, Stevens CR, Winyard PG, Mills PG, Blake DR: Modified low density lipoprotein and cytokines mediate monocyte adhesion to smooth muscle cells. Atherosclerosis 1996;127:167-176.

56 Wright PS, Cooper JR, Kropp KE, Busch SJ: Induction of vascular cell adhesion molecule-1 expression by IL-4 in human aortic smooth muscle cells is not associated with increased nuclear NF- $\mathrm{BB}$ levels. J Cell Physiol 1999;180:381-389.

57 Chen L, Frister A, Wang S, Ludwig A, Behr H, Pippig S, Li B, Simm A, Hofmann B, Pilowski C, Koch S, Buerke M, Rose-John S, Werdan K, Loppnow H: Interaction of vascular smooth muscle cells and monocytes by soluble factors synergistically enhances interleukin-6 and MCP-1 production. Am Physiol Heart Circ Physiol 2009;296:H987H996.

58 Jiang B, Xu S, Hou X, Pimentel DR, Cohen RA: Angiotensin II differentially regulates interleukin-1-beta-inducible NO synthase (iNOS) and vascular cell adhesion molecule1 (VCAM-1) expression: role of p38 MAPK. J Biol Chem 2004:279:20363-20368.

-59 Della Bella S, Molteni M, Mocellin C, Fumagalli S, Bonara P, Scorza R: Novel mode of action of iloprost: in vitro down-regulation of endothelial cell adhesion molecules. Prostaglandins Other Lipid Mediat 2001;65:7383.

60 Ouchi N, Kihara S, Arita Y, Okamoto Y, Maeda K, Kuriyama H, Hotta K, Nishida M, Takahashi M, Muraguchi M, Ohmoto Y, Nakamura T, Yamashita S, Funahashi T, Matsuzawa Y: Adiponectin, an adipocyte-derived plasma protein, inhibits endothelial NF- $\kappa B$ signaling through a cAMP-dependent pathway. Circulation 2000;102:1296-1301.

61 Braun M, Pietsch P, Zepp A, Schror K, Baumann G, Felix SB: Regulation of tumor necrosis factor alpha- and interleukin-1-betainduced induced adhesion molecule expression in human vascular smooth muscle cells by cAMP. Arterioscler Thromb Vasc Biol 1997;17:2568-2575.
62 Kawamura A, Baitsch D, Telgmann R, Feuerborn R, Weissen-Plenz G, Hagedorn C, Saku K, Brand-Herrmann SM, von Eckardstein A, Assmann G, Nofer JR: Apolipoprotein E interrupts interleukin- $1 \beta$ signaling in vascular smooth muscle cells. Arterioscler Thromb Vasc Biol 2007;27:1610-1617.

-63 Speir E, Yu ZX, Takeda K, Ferrans VJ, Cannon RO 3rd: Competition for $\mathrm{p} 300$ regulates transcription by estrogen receptors and nuclear factor- $\kappa \mathrm{B}$ in human coronary smooth muscle cells. Circ Res 2000;87:1006-1011.

64 Nie M, Corbett L, Knox AJ, Pang L: Differential regulation of chemokine expression by peroxisome proliferator-activated receptor gamma agonists: interactions with glucocorticoids and $\beta_{2}$-agonists. J Biol Chem 2005; 280:2550-2561.

65 Barnes MJ, Farndale RW: Collagens and atherosclerosis. Exp Gerontol 1999;34:513-525.

66 Moiseeva EP: Adhesion receptors of vascular smooth muscle cells and their functions. Cardiovasc Res 2001;52:372-386.

67 Molossi S, Clausell N, Rabinovitch M: Reciprocal induction of tumor necrosis factor-alpha and interleukin-1 beta activity mediates fibronectin synthesis in coronary artery smooth muscle cells. J Cell Physiol 1995;163: 19-29.

68 Qwarnstrom EE, Ostberg CO, Turk GL, Richardson CA, Bomsztyk K: Fibronectin attachment activates the NF-kappa B p50/ p65 heterodimer in fibroblasts and smooth muscle cells. J Biol Chem 1994;269:3076530768.

-69 Yin BL, Hao H, Wang YY, Jiang YJ, Xue S: Downregulating osteopontin reduces angiotensin II-induced inflammatory activation in vascular smooth muscle cells. Inflamm Res 2009;58:67-73.

70 Kappert K, Blaschke F, Meehan WP, Kawano $\mathrm{H}$, Grill M, Fleck E, Hsueh WA, Law RE, Graf K: Integrins $\alpha_{\mathrm{v}} \beta_{3}$ and $\alpha_{\mathrm{v}} \beta_{5}$ mediate VSMC migration and are elevated during neointima formation in the rat aorta. Basic Res Cardiol 2001;96:42-49.

71 Mawatari K, Liu B, Kent KC: Activation of integrin receptors is required for growth factor-induced smooth muscle cell dysfunction. J Vasc Surg 2000;31:375-381.

72 Scatena M, Almeida M, Chaisson ML, Fausto N, Nicosia RF, Giachelli CM: NF-кB mediates $\alpha_{\mathrm{v}} \beta_{3}$ integrin-induced endothelial cell survival. J Cell Biol 1998;141:1083-1093.

73 Klein S, de Fougerolles AR, Blaikie P, Khan L, Pepe A, Green CD, Koteliansky V, Giancotti FG: $\alpha 5 \beta 1$ integrin activates an NF- $\kappa B$-dependent program of gene expression important for angiogenesis and inflammation. Mol Cell Biol 2002;22:5912-5922.

-74 Cuff CA, Kothapalli D, Azonobi I, Chun S, Zhang Y, Belkin R, Yeh C, Secreto A, Assoian RK, Rader DJ, Pure E: The adhesion receptor CD44 promotes atherosclerosis by mediating inflammatory cell recruitment and vascular cell activation. J Clin Invest 2001;108: 1031-1040. 
75 Koyama H, Raines EW, Bornfeldt KE, Roberts JM, Ross R: Fibrillar collagen inhibits arterial smooth muscle proliferation through regulation of Cdk2 inhibitors. Cell 1996;87: 1069-1078.

-76 Yamamoto M, Yamamoto K, Noumura T: Type I collagen promotes modulation of cultured rabbit arterial smooth muscle cells from a contractile to a synthetic phenotype. Exp Cell Res 1993;204:121-129.

$\checkmark 77$ Bond M, Chase AJ, Baker AH, Newby AC: Inhibition of transcription factor NF- $\kappa \mathrm{B}$ reduces matrix metalloproteinase-1, -3 and -9 production by vascular smooth muscle cells. Cardiovasc Res 2001;50:556-565.

$\checkmark 78$ Minami T, Miura M, Aird WC, Kodama T: Thrombin-induced autoinhibitory factor, Down syndrome critical region-1, attenuates NFAT-dependent vascular cell adhesion molecule-1 expression and inflammation in the endothelium. J Biol Chem 2006;281: 20503-20520.

79 Heino J: The collagen receptor integrins have distinct ligand recognition and signaling functions. Matrix Biol 2000;19:319-323.

$>80$ Chung $\mathrm{CH}$, Lin KT, Chang $\mathrm{CH}$, Peng HC, Huang TF: The integrin $\alpha_{2} \beta_{1}$ agonist, aggretin, promotes proliferation and migration of VSMC through NF- $\kappa \mathrm{B}$ translocation and PDGF production. Br J Pharmacol 2009;156: 846-856.

-81 Skinner MP, Raines EW, Ross R: Dynamic expression of alpha 1 beta 1 and alpha 2 beta 1 integrin receptors by human vascular smooth muscle cells. Alpha 2 beta 1 integrin is required for chemotaxis across type I collagen-coated membranes. Am J Pathol 1994; 145:1070-1081.

82 Hou G, Vogel WF, Bendeck MP: Tyrosine kinase activity of discoidin domain receptor 1 is necessary for smooth muscle cell migration and matrix metalloproteinase expression. Circ Res 2002;90:1147-1149.

83 Franco C, Hou G, Ahmad PJ, Fu EY, Koh L, Vogel WF, Bendeck MP: Discoidin domain receptor 1 (ddr1) deletion decreases atherosclerosis by accelerating matrix accumulation and reducing inflammation in low-density lipoprotein receptor-deficient mice. Circ Res 2008;102:1202-1211.

84 Hahn C, Schwartz MA: Mechanotransduction in vascular physiology and atherogenesis. Nat Rev Mol Cell Biol 2009;10:53-62.

-85 Dardik A, Yamashita A, Aziz F, Asada H, Sumpio BE: Shear stress-stimulated endothelial cells induce smooth muscle cell chemotaxis via platelet-derived growth factorBB and interleukin-1 $\alpha$. J Vasc Surg 2005;41: 321-331.

-86 Dai G, Kaazempur-Mofrad MR, Natarajan S, Zhang Y, Vaughn S, Blackman BR, Kamm RD, Garcia-Cardena G, Gimbrone MA Jr: Distinct endothelial phenotypes evoked by arterial waveforms derived from atherosclerosis-susceptible and -resistant regions of human vasculature. Proc Natl Acad Sci USA 2004;101:14871-14876.
87 Blackman BR, Garcia-Cardena G, Gimbrone MA Jr: A new in vitro model to evaluate differential responses of endothelial cells to simulated arterial shear stress waveforms. J Biomech Eng 2002;124:397-407.

88 Birukov KG, Shirinsky VP, Stepanova OV, Tkachuk VA, Hahn AW, Resink TJ, Smirnov VN: Stretch affects phenotype and proliferation of vascular smooth muscle cells. Mol Cell Biochem 1995;144:131-139.

89 Hishikawa K, Oemar BS, Yang Z, Luscher TF: Pulsatile stretch stimulates superoxide production and activates nuclear factor-kappa B in human coronary smooth muscle. Circ Res 1997;81:797-803.

90 Guest TM, Vlastos G, Alameddine FM, Taylor WR: Mechanoregulation of monocyte chemoattractant protein-1 expression in rat vascular smooth muscle cells. Antioxid Redox Signal 2006;8:1461-1471.

91 Katsumi A, Milanini J, Kiosses WB, del Pozo MA, Kaunas R, Chien S, Hahn KM, Schwartz MA: Effects of cell tension on the small GTPase Rac. J Cell Biol 2002;158:153-164.

92 Hordijk PL: Regulation of NADPH oxidases: the role of Rac proteins. Circ Res 2006;98: 453-462.

93 Zampetaki A, Zhang Z, Hu Y, Xu Q: Biomechanical stress induces IL-6 expression in smooth muscle cells via Ras/Rac1-p38 MAPK-NF- $\mathrm{B}$ signaling pathways. Am J Physiol Heart Circ Physiol 2005;288:H2946H2954.

94 Chiu JJ, Chen LJ, Chen CN, Lee PL, Lee CI A model for studying the effect of shear stress on interactions between vascular endothelial cells and smooth muscle cells. J Biomech 2004;37:531-539.

95 Harris TA, Yamakuchi M, Ferlito M, Mendell JT, Lowenstein CJ: MicroRNA-126 regulates endothelial expression of vascular cell adhesion molecule 1. Proc Natl Acad Sci USA 2008;105:1516-1521.

-96Pedersen I, David M: MicroRNAs in the immune response. Cytokine 2008;43:391-394.

97 Urbich C, Kuehbacher A, Dimmeler S: Role of microRNAs in vascular diseases, inflammation, and angiogenesis. Cardiovasc Res 2008;79:581-588.

$\checkmark 98$ Tili E, Michaille JJ, Cimino A, Costinean S, Dumitru CD, Adair B, Fabbri M, Alder H, Liu CG, Calin GA, Croce CM: Modulation of miR-155 and miR-125b levels following lipopolysaccharide/TNF-alpha stimulation and their possible roles in regulating the response to endotoxin shock. J Immunol 2007; 179:5082-5089.

$>99$ O'Connell RM, Taganov KD, Boldin MP, Cheng G, Baltimore D: MicroRNA-155 is induced during the macrophage inflammatory response. Proc Natl Acad Sci USA 2007;104: 1604-1609.
100 Martin MM, Buckenberger JA, Jiang J, Malana GE, Nuovo GJ, Chotani M, Feldman DS, Schmittgen TD, Elton TS: The human angiotensin II type 1 receptor +1166 A/C polymorphism attenuates microRNA155 binding. J Biol Chem 2007;282:2426224269.

101 Barreau C, Paillard L, Osborne HB: AUrich elements and associated factors: are there unifying principles? Nucleic Acids Res 2005;33:7138-7150.

102 Anderson P: Post-transcriptional control of cytokine production. Nat Immunol 2008;9: 353-359.

103 Jagavelu K, Tietge UJ, Gaestel M, Drexler H, Schieffer B, Bavendiek U: Systemic deficiency of the MAP kinase-activated protein kinase 2 reduces atherosclerosis in hypercholesterolemic mice. Circ Res 2007;101: 1104-1112.

104 Ohh M, Smith CA, Carpenito C, Takei F: Regulation of intercellular adhesion molecule-1 gene expression involves multiple mRNA stabilization mechanisms: effects of interferon-gamma and phorbol myristate acetate. Blood 1994;84:2632-2639.

105 Raineri I, Wegmueller D, Gross B, Certa U, Moroni C: Roles of AUF1 isoforms, HuR and BRF1 in ARE-dependent mRNA turnover studied by RNA interference. Nucleic Acids Res 2004;32:1279-1288.

106 Carballo E, Gilkeson GS, Blackshear PJ: Bone marrow transplantation reproduces the tristetraprolin-deficiency syndrome in recombination activating gene-2(-/-) mice. Evidence that monocyte/macrophage progenitors may be responsible for TNF $\alpha$ overproduction. J Clin Invest 1997;100:986995.

107 Carballo E, Lai WS, Blackshear PJ: Evidence that tristetraprolin is a physiological regulator of granulocyte-macrophage colony-stimulating factor messenger RNA deadenylation and stability. Blood 2000;95: 1891-1899.

108 Chrestensen CA, Schroeder MJ, Shabanowitz J, Hunt DF, Pelo JW, Worthington MT, Sturgill TW: MAPKAP kinase 2 phosphorylates tristetraprolin on in vivo sites including Ser178, a site required for 14-3-3 binding. J Biol Chem 2004;279:10176-10184.

109 Stoecklin G, Stubbs T, Kedersha N, Wax S, Rigby WF, Blackwell TK, Anderson P: MK2-induced tristetraprolin:14-3-3 complexes prevent stress granule association and ARE-mRNA decay. EMBO J 2004;23: 1313-1324.

10 Sun L, Stoecklin G, Van Way S, HinkovskaGalcheva V, Guo RF, Anderson P, Shanley TP: Tristetraprolin (TTP)-14-3-3 complex formation protects TTP from dephosphorylation by protein phosphatase $2 \mathrm{a}$ and stabilizes tumor necrosis factor-alpha mRNA. J Biol Chem 2007;282:3766-3777. 
-111 Croft D, McIntyre P, Wibulswas A, Kramer I: Sustained elevated levels of VCAM-1 in cultured fibroblast-like synoviocytes can be achieved by TNF-alpha in combination with either IL-4 or IL-13 through increased mRNA stability. Am J Pathol 1999;154: 1149-1158.

112 Hay N, Sonenberg N: Upstream and downstream of mTOR. Genes Dev 2004;18:19261945.

-113 Cully M, Downward J: Translational responses to growth factors and stress. Biochem Soc Trans 2009;37:284-288.

-114 Schreml S, Lehle K, Birnbaum DE, Preuner JG: mTOR-inhibitors simultaneously inhibit proliferation and basal IL- 6 synthesis of human coronary artery endothelial cells. Int Immunopharmacol 2007;7:781-790.

-115 Waskiewicz AJ, Flynn A, Proud CG, Cooper JA: Mitogen-activated protein kinases activate the serine/threonine kinases Mnk1 and Mnk2. EMBO J 1997;16:1909-1920.

-116 Pyronnet S: Phosphorylation of the capbinding protein eIF4E by the MAPK-activated protein kinase Mnk1. Biochem Pharmacol 2000;60:1237-1243.

-117 Andersson K, Sundler R: Posttranscriptional regulation of $\mathrm{TNF} \alpha$ expression via eukaryotic initiation factor $4 \mathrm{E}$ (eIF4E) phosphorylation in mouse macrophages. Cytokine 2006;33:52-57.
118 Wang X, Flynn A, Waskiewicz AJ, Webb BL, Vries RG, Baines IA, Cooper JA, Proud CG: The phosphorylation of eukaryotic initiation factor eIF4E in response to phorbol esters, cell stresses, and cytokines is mediated by distinct MAP kinase pathways. J Biol Chem 1998;273:9373-9377.

119 Kjellerup RB, Kragballe K, Iversen L, Johansen C: Pro-inflammatory cytokine release in keratinocytes is mediated through the MAPK signal-integrating kinases. Exp Dermatol 2008;17:498-504.

120 Buxade M, Parra JL, Rousseau S, Shpiro N, Marquez R, Morrice N, Bain J, Espel E, Proud CG: The Mnks are novel components in the control of TNF alpha biosynthesis and phosphorylate and regulate hnRNP A1. Immunity 2005;23:177-189.

121 Ishida M, Ishida T, Nakashima H, Miho N, Miyagawa K, Chayama K, Oshima T, Kambe $M$, Yoshizumi M: Mnk1 is required for angiotensin II-induced protein synthesis in vascular smooth muscle cells. Circ Res 2003;93:1218-1224.

122 Dominguez C, Powers DA, Tamayo N: p38 MAP kinase inhibitors: many are made, but few are chosen. Curr Opin Drug Discov Devel 2005;8:421-430.
123 Nahrendorf M, Jaffer FA, Kelly KA, Sosnovik DE, Aikawa E, Libby P, Weissleder R: Noninvasive vascular cell adhesion molecule-1 imaging identifies inflammatory activation of cells in atherosclerosis. Circulation 2006;114:1504-1511.

124 Phillips LC, Klibanov AL, Bowles DK, Ragosta M, Hossack JA, Wamhoff BR: Focused in vivo delivery of plasmid DNA to the porcine vascular wall via intravascular ultrasound destruction of microbubbles. J Vasc Res 2010; in press.

125 Kaufmann BA, Sanders JM, Davis C, Xie A, Aldred P, Sarembock IJ, Lindner JR: Molecular imaging of inflammation in atherosclerosis with targeted ultrasound detection of vascular cell adhesion molecule-1. Circulation 2007;116:276-284.

126 Isner JM, Kearney M, Bortman S, Passeri J: Apoptosis in human atherosclerosis and restenosis. Circulation 1995;91:2703-2711.

127 Swirski FK, Weissleder R, Pittet MJ: Heterogeneous in vivo behavior of monocyte subsets in atherosclerosis. Arterioscler Thromb Vasc Biol, E-pub ahead of print.

128 Wamhoff BR, Sinha S, Owens GK: Conditional mouse models to study developmental and pathophysiological gene function in muscle; in Feil R, Metzger D (eds): Conditional Mutagenesis: An Approach to Disease Models. Berlin, Springer, 2007, vol 178, pp 441-468. 